\title{
EHMTI-0288. A clinical comparison demonstrates similarities between chronic and high frequency episodic migraine
}

\author{
P Pozo-Rosich 1*, M Quintana ${ }^{1}$, M Torres $^{1}$, J Fernandez-Morales², J Alvarez-Sabin ${ }^{1}$ \\ From 4th European Headache and Migraine Trust International Congress: EHMTIC 2014 \\ Copenhagen, Denmark. 18-21 September 2014
}

To do a clinical comparison in migraine according to the number of headache days suffered per month

According to the IHCD-III beta, migraine can be classified as episodic migraine (intuitively) and chronic migraine (CM). 1109 patients were analyzed and divided into three different groups: low-frequency episodic migraine (LFEM: 0-9 days/month), high-frequency episodic migraine (HFEM: 10-14 days/months) and chronic migraine ( $C M \geq 15$ days/month). Clinical characteristics (sociodemographics, comorbid diseases, frequency, treatments, disability -MIDAS-, impact -HIT6-, anxiety -STAI-, and depression -BDI- were analyzed using first an univariate analysis and then a logistic regression model.

Differences have been found between the LFEM-HFEM and LFEM-CM. Between LFEM-HFEM, three risk factors have been observed associated in an independent manner: medication overuse $[\mathrm{OR}=19.21$; IC(5.50-67.05); $\mathrm{p}<$ 0.001 ], MIDAS scale disability [OR $=1.47$; IC(1.24-1.74); $\mathrm{p}<0.001]$ and the presence of compressive type pain [OR = 1.77; IC(1.21-2.59); $\mathrm{p}<0.05]$. Between LFEM and $\mathrm{CM}$, three independent risk factors have been independently associated with CM: medication overuse [OR = 20.74; IC(3.07-140.23); $\mathrm{p}<0.05$ ], BDI-II scale grade $[\mathrm{OR}=1.77$; IC(1.24-2.54); $\mathrm{p}<0.05]$ and verbal analysis of pain. No differences were found between HFEM and CM except for the frequency and duration of the attacks.

$\mathrm{CM}$ is defined as suffering from headache and migraine on 15 or more days. However, this division is arbitrary. Our study demonstrates that CM and HFEM are practically the same, and that LFEM is different from HFEM and CM. This creates reasonable doubts regarding the chronification of migraine and when to consider a patient

${ }^{1}$ Neurology, Hospital Universitari Vall d'Hebron, Barcelona, Spain

Full list of author information is available at the end of the article to be chronic. We propose that HFEM patients be considered as CM.

No conflict of interest.

Authors' details

${ }^{1}$ Neurology, Hospital Universitari Vall d'Hebron, Barcelona, Spain. ${ }^{2}$ Headache Research Lab, Vall d'Hebron Research Institute, Barcelona, Spain.

Published: 18 September 2014

doi:10.1186/1129-2377-15-S1-E28

Cite this article as: Pozo-Rosich et al:: EHMTI-0288. A clinical comparison demonstrates similarities between chronic and high frequency episodic migraine. The Journal of Headache and Pain 2014 15(Suppl 1):E28.

Submit your manuscript to a SpringerOpen ${ }^{\odot}$ journal and benefit from:

- Convenient online submission

- Rigorous peer review

- Immediate publication on acceptance

- Open access: articles freely available online

- High visibility within the field

- Retaining the copyright to your article

Submit your next manuscript at $\boldsymbol{~ s p r i n g e r o p e n . c o m ~}$
(C) 2014 Pozo-Rosich et al; licensee Springer. This is an Open Access article distributed under the terms of the Creative Commons Attribution License (http://creativecommons.org/licenses/by/2.0), which permits unrestricted use, distribution, and reproduction in any medium, provided the original work is properly cited. 